\title{
A life-cycle perspective on the transition to adulthood among children receiving Supplemental Security Income payments
}

\author{
Paul S. Davies ${ }^{\mathrm{a}, *}$, Kalman Rupp $^{\mathrm{a}}$ and David Wittenburg ${ }^{\mathrm{b}}$

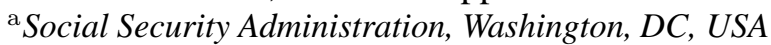 \\ ${ }^{\mathrm{b}}$ Mathematica Policy Research, Princeton, NJ, USA
}

Received 25 February 2009

\begin{abstract}
Youth who receive cash benefits from the Supplemental Security Income (SSI) program, the largest federal program that provides cash payments to low-income youth with severe disabilities and their families, face several challenges in transitioning into adulthood. From a human capital development perspective, the disabilities and health problems during childhood and early adulthood as well as the family environment form important inputs that will likely influence long-term adult outcomes. This paper provides a review of some of the challenges these youth face in transitioning into adulthood using a life-cycle framework and presents descriptive statistics on their challenges and outcomes into early adulthood. Our summary illustrates the challenges that SSI youth face as they make the transition to adulthood and shows how the long-term employment and program outcomes of this population have changed over time. The findings provide a broader framework for the remaining five papers in this issue and underscore the need for rigorous testing of promising interventions and a carefully balanced mix of statistical and econometric analyses based on longitudinal data sources with a long time horizon.
\end{abstract}

Keywords: Supplemental Security Income, SSI, transition, youth, disabilities, Social Security, SSA, human capital development, evaluation, random assignment

\section{The life-cycle context of youth transitions}

The Supplemental Security Income (SSI) program is the largest federal program that provides cash payments to low-income youth with severe disabilities. These youth face the dual challenges of severe health problems and disabilities and being raised in a family environment of economic hardship. A growing body of empirical literature demonstrates that severe health problems and disabilities in childhood are associated with limited human capital development and negative labor market outcomes in adulthood: low rates of em-

* Address for correspondence: Paul S. Davies, Social Security Administration, 500 E Street SW Room 922, Washington, DC 20254 USA. Tel.: +1 202358 6277; Fax: +1 202358 6187; E-mail paul.davies@ssa.gov. ployment, high risk of unemployment, low wages, and continued reliance on public benefits $[3,25,26]$. Similar outcomes have been observed for children who grow up in families affected by poverty [4,17]. Due to the intersection of the dual challenges affecting SSI youth, programs designed to facilitate successful transition into adulthood face enormous challenges.

From the perspective of human capital development, the disabilities and health problems during childhood and early adulthood as well as the family environment form important inputs that will likely influence longterm adult outcomes. Children who receive SSI benefits likely have needs for extra attention and caregiving from their family members to address physical and/or mental issues related to their disabilities. They also might need more substantial health care and supportive services that are relatively costly compared with 
the needs of other youth. Education is another area in which child SSI recipients might need extra attention, accommodations, and services to accumulate the human capital needed to become self-sufficient and successful in the labor market and society [33]. The needs change as children grow from infancy to adulthood. A variety of public supports and programs are available to enhance their human capital development and aid the transition to adulthood. These programs include cash and in-kind public benefits (for example, Medicaid, Food Stamps, and housing assistance). In recent years, the Social Security Administration (SSA) has developed employment-oriented interventions focusing on childhood SSI recipients and young adults with the goal of improving long-term labor market outcomes; the Youth Transition Demonstration (YTD) currently offers employment supports and work incentives to child and young adult SSI recipients (ages 14 to 25).

This paper provides a review of some of the challenges these youth face transitioning into adulthood using a life-cycle framework and presents descriptive statistics on their challenges and outcomes into early adulthood. We begin with an overview of SSI program rules, which illustrates the complex eligibility requirements that shape the childhood SSI caseload. We then use a life-cycle framework to examine various factors affecting a youth's transition into adulthood, including impairment, family environment, and availability of public supports (education and other programs). In developing this framework, we provide descriptive data from SSA's National Survey of SSI Children and Families (NSCF). Finally, we present new data on longterm program and employment outcomes of SSI youth (based on longitudinal SSA administrative records) that underscore the potential need for interventions such as YTD.

The findings should be of great interest to researchers, policy makers, and practitioners who want to understand better the transition process and long-term outcomes of SSI youth. Our paper illustrates the challenges that children who receive SSI face and shows how the long-term employment and program outcomes of this population have changed over time. Additionally, it provides a framework for how researchers, practitioners, and policy makers should think about developing interventions to serve child SSI recipients. Finally, the findings provide contextual information for the remaining five papers in this issue.

\section{The Supplemental Security Income program for children with disabilities}

Established by Congress in 1972, SSI is a cash assistance program administered by the SSA that provides an important source of cash benefits for low-income people who meet certain criteria. The program was designed to assure a minimum level of cash income for aged, blind, and disabled individuals who meet the requirements of a means test and satisfy certain citizenship and residency requirements. The SSI federal income guarantee is called the Federal Benefit Rate (FBR). The 2009 FBR is \$674 per month for individuals and $\$ 1,011$ per month for couples and represents the maximum federal benefit that can be paid. The actual monthly benefit is calculated as the FBR less certain forms of income (after some exclusions) from non-SSI sources. Optional state supplements available in most states raise the maximum combined (federal plus state) benefit above the FBR, in some cases substantially [30]. SSI is a categorical cash assistance program in that eligibility is not universal among people meeting the SSI means test, but rather is limited to two categories of qualifying United States citizens/residents: (1) people who are age 65 or older (regardless of disability) and (2) people ages 0 to 64 who meet the statutory definition of disability. Many in-kind benefit programs treat SSI recipients as categorically eligible. The most important of these is Medicaid, although some states use more restrictive criteria for Medicaid eligibility or require a separate Medicaid application [29]. Interactions between SSI and Food Stamps also are important [32].

\subsection{The disability screen}

The SSI disability screen for children evolved from the adult criteria that were first developed for the Social Security Disability Insurance (DI) program and were adopted by SSI from the program's onset without any change. Both programs use the same adjudicative mechanism - the state Disability Determination Services (DDSs). The statutory definition of disability requires that the adult applicant have a medically determinable physical or mental impairment that is expected to last or has lasted at least 12 months or is expected to result in death and prevents the applicant from doing any substantial gainful activity. SSA's regulations outline a sequential evaluation process. SSA [28] provides a detailed description of the disability determination process. The substantial gainful activity (SGA) test performed by SSA field offices compares monthly 
earnings with the SGA threshold, which in 2009 was $\$ 980$ for non-blind individuals. If an applicant earns more than the SGA threshold, he or she is screened out as not categorically disabled. For those who pass the SGA screen, the file is transferred to the DDS, which establishes whether the impairment meets the severity and duration requirements, and whether the impairment meets or medically equals a condition listed in SSA's Adult Listings of Impairments [28]. If the conditions are met, the claim is allowed. If not, the DDS considers a series of vocational factors, which are intended to determine whether the individual can do any type of work available in the national economy.

The SSI program has struggled with the application of the disability screen for children ages 0 to 17 , and major changes in the SSI program for children have been motivated by concerns about the operationalization of the disability screen. The 1972 law (P.L. 92603 ) that established the SSI program stated that for a child under age 18, eligibility is based on disability of severity comparable with that of an adult. The comparable severity concept was translated into regulations that essentially ignored the front and back ends of the disability determination process as applied to adults. Before 1990, the core of the disability screen for nonworking children was the Listings of Impairments. The focus of the test was whether a child had a condition that met or medically equaled the Adult Listings of Impairments or a supplemental set of Childhood Listings of Impairments. Children who did not pass this test were never considered further. Although some adults were disqualified by the SGA requirement, no comparable screening-out rule applied to nonworking minors. Note that, formally, the SGA screen has been applied to children as well from the beginning of the SSI program [27]. However, because most children do not and are not supposed to work, the SGA test fails to act for children as a meaningful screening-out tool. Likewise, although adults not meeting or medically equaling the Listings of Impairments could still qualify based on vocational factors, no comparable screening-in rule was applied to children.

Two important modifications in 1990 resulted in the dramatic expansion of the childhood SSI program. SSA modified the section of the Listings of Impairments dealing with childhood mental disorders, moving toward a more functionally based assessment of a child's categorical eligibility. The 1990 Supreme Court decision Sullivan v. Zebley resulted in a more fundamental change. Brian Zebley, born in 1978, enrolled in SSI as a toddler and was removed from SSI at the age of
5 during a period in which the administration of SSA's disability programs tightened. He "suffered from congenital brain damage, mental retardation, visual problems, development delays, and partial paralysis. . . Begun as a little noticed denial of benefits, Sullivan v. Zebley evolved into a major class action lawsuit, representing more than 300,000 children" [9]. The Supreme Court argued that SSA's "Listings-Only" approach toward determining disability in children did not carry out the comparable severity standard of the Social Security Act, in that the Listings of Impairments were set at a level of severity stricter than the level at which an adult can be found disabled. The Court ordered SSA to include an individual assessment for children. SSA issued regulations to implement an individual functional assessment (IFA) to determine whether a child could function "independently, appropriately, and effectively in an age-appropriate manner." The Zebley decision called for a redetermination of all childhood denials since 1980, and the new disability standards substantially broadened the definition of childhood disability. A surge in the childhood SSI caseload resulted [9].

Following heavy criticism of the less-strict criteria resulting from these changes, the 1996 welfare reform legislation (P.L. 104-193) eliminated the IFA (although it retained functional evaluations of children), eliminated references to "maladaptive behaviors" from the Listings of Impairments, and required redetermination of the categorical eligibility of child recipients after their 18 th birthdays using the adult criteria. The caseload initially dropped. More than 100,000 children were removed from the rolls and 45 percent of the first cohort of age-18 redeterminations resulted in cessation of benefits [20]. Over time, however, the child SSI program continued to grow, with total enrollment now surpassing its pre-welfare reform level [29].

\subsection{Income test}

In addition to meeting the disability requirements, SSI recipients must meet an income and resource test. In determining income eligibility, certain items are excluded, such as state or locally funded assistance, government-provided rent subsidies, impairment-related work expenses for the disabled (any work expenses for the blind), and income set aside for a plan to achieve self-support. For income items not specifically excluded, the first $\$ 20$ of income from any source is excluded; an additional $\$ 65$ of any earned income is excluded. Finally, 50 percent of any earnings greater than $\$ 65$ are excluded [29]. The student earned in- 
come exclusion allows recipients under age 22 and regularly attending school to exclude all earnings up to a certain level from countable income. These income exclusions were designed, at least in part, to serve as work incentives for SSI recipients [31]. The result of these calculations is "countable income." If countable income is less than the FBR, federal income eligibility is the result. (A few cases in which countable income equals or exceeds the FBR may still qualify for state-only benefits.)

An additional income-related provision is the deeming of the income of ineligible spouses and parents, which is particularly important for understanding the child SSI program. A child under age 18 is subject to deeming from an ineligible parent living in the same house. This basically means that countable deemed income of an ineligible parent is considered to be available to a child and is counted in the income test for that child. SSA follows similar rules for establishing countable deemed income from a parent as discussed above for individual SSI applicants, but additional exclusions apply (living allowances for the parent(s) and each ineligible child under age 18 or under age 21 if the child is a student). Parental income from public income maintenance programs, including SSI, is not deemed to be available to a child. Parental deeming increases countable income, which might lead to either income ineligibility for a child or a reduced SSI benefit [29].

\subsection{Resource test}

For an unmarried child to pass the resource test, countable resources must not exceed $\$ 2,000$. As with income, certain assets are excluded in establishing resource eligibility, such as a home used as the principal residence, one automobile, household goods and personal effects, property essential to self-support, resources set aside to fulfill a plan to achieve self-support, and amounts deposited into an individual development account. Parental deeming also applies to the establishment of resource eligibility [29].

\section{Disability challenges, family environment, and public inputs affecting the human capital development of an SSI recipient child}

The challenges facing the human capital development of a child arise from three major sources: (1) the nature and extent of a child's disabilities, (2) strengths and weaknesses of the family environment, and (3) strengths and weaknesses of the public institutions in addressing the challenges arising from both (1) and (2). To illuminate these issues, in this section we provide a brief overview of a nationally representative cross section of noninstitutional children that receive SSI based on the NSCF. (Public use data and documentation on the NSCF are available at http://www.socialsecurity.gov/disabilityresearch/nscf. htm.) Because the NSCF was conducted during 20002001, these data are somewhat dated, but no major change of the program occurred in the interim; the data should give a reasonable indication of the characteristics of these children, their families, and the program environment today. Most of the empirical data presented in this section reflect a subset of a more extensive array of descriptive data that was presented in Rupp et al. [21]. In the tables to follow we provide estimates for three age subgroups: 0 to 5, 6 to 13 , and 14 to 17 . (Standard errors for all estimates in Tables 1-3 are available from the authors upon request.) The age groups reflect three distinct developmental stages relevant for human capital development roughly corresponding to the preschool, elementary and middle school, and high school age groups. The characteristics and needs of children might differ substantially as a function of their age, and there might be important differences in the family and program environment for the three groups. We identify both commonalities and distinct patterns for the three developmental stages. Finally, we discuss the unique challenges facing transition-age youth.

\subsection{Characteristics of the SSI recipient child}

Table 1 highlights the demographic composition of SSI youth and various measures of the nature and extent of disabilities and health-related indicators. Of particular interest is the fact that children are roughly equally divided by primary impairment, as reflected in SSA administrative records, into three groups: mental retardation, mental and behavioral disorders, and other primary impairments (predominantly physical disabilities). There is a clear association between current age and primary impairment. Many of the transition-age SSI recipients (14-17 years of age) entered at earlier ages in childhood; 67 percent entered SSI under the age of 10 . The differences in primary impairments are even more pronounced by age at entry (not shown here). This means that many transition-age youth have been affected by the SSI environment for several years, in some cases from birth. The other items in Table 1 indicate substantial heterogeneity in the perceived nature 
Table 1

Characteristics of children receiving SSI in December 2000, by age group

\begin{tabular}{|c|c|c|c|c|}
\hline & \multirow{3}{*}{$\begin{array}{c}\text { All child SSI } \\
\text { recipients } \\
\text { Ages } \\
0-17\end{array}$} & \multicolumn{3}{|c|}{$\begin{array}{c}\text { Child SSI recipients } \\
\text { by age group }\end{array}$} \\
\hline & & Ages & Ages & Ages \\
\hline & & $0-5$ & $6-13$ & $14-17$ \\
\hline \multicolumn{5}{|l|}{ Sample Size } \\
\hline Weighted N & 791,954 & 154,492 & 421,629 & 215,834 \\
\hline Percentage (Weighted) & 100.0 & 19.5 & 53.2 & 27.3 \\
\hline \multicolumn{5}{|l|}{ Gender } \\
\hline Female & 36.1 & 40.8 & 34.3 & 36.3 \\
\hline Male & 63.9 & 59.2 & 65.7 & 63.7 \\
\hline \multicolumn{5}{|l|}{ Race } \\
\hline White alone & 47.2 & 47.2 & 46.6 & 48.3 \\
\hline Black alone & 46.2 & 43.1 & 47.2 & 46.5 \\
\hline American Indian, Alaska Native, Asian or Pacific Islander alone & 2.9 & 3.3 & 2.9 & 2.5 \\
\hline Multiracial & 3.7 & 6.4 & 3.2 & 2.7 \\
\hline \multicolumn{5}{|l|}{ Ethnicity } \\
\hline Hispanic & 16.3 & 18.0 & 16.5 & 14.5 \\
\hline Not Hispanic & 83.8 & 82.0 & 83.5 & 85.5 \\
\hline \multicolumn{5}{|l|}{ Age at Program Entry ${ }^{a}$} \\
\hline Under 10 & 86.7 & 100.0 & 92.1 & 66.8 \\
\hline 10 to 13 & 11.0 & $\mathrm{n} / \mathrm{a}$ & 7.9 & 24.7 \\
\hline 14 to 17 & 2.3 & $\mathrm{n} / \mathrm{a}$ & $\mathrm{n} / \mathrm{a}$ & 8.5 \\
\hline \multicolumn{5}{|l|}{ SSA Primary Impairment } \\
\hline Mental retardation (MR) & 32.5 & 10.5 & 34.0 & 45.4 \\
\hline Mental and behavioral disorders (other than MR) & 29.2 & 18.0 & 32.9 & 30.0 \\
\hline Physical disabilities and systems disorders & 25.4 & 39.0 & 24.0 & 18.4 \\
\hline Other disabilities & 7.7 & 26.0 & 4.2 & 1.7 \\
\hline \multicolumn{5}{|l|}{ Number of Functional Limitations } \\
\hline Zero & $\mathrm{b}$ & $\mathrm{b}$ & 62.7 & 78.8 \\
\hline One & $\mathrm{b}$ & $\mathrm{b}$ & 6.3 & 4.5 \\
\hline Two & $\mathrm{b}$ & $\mathrm{b}$ & 11.4 & 5.4 \\
\hline Three to six & $\mathrm{b}$ & $\mathrm{b}$ & 19.3 & 11.1 \\
\hline \multicolumn{5}{|l|}{ Functional Limitations, Needs Help - } \\
\hline Getting in and out of bed & $\mathrm{b}$ & $\mathrm{b}$ & 9.6 & 6.4 \\
\hline Getting around inside home & $\mathrm{b}$ & $\mathrm{b}$ & 8.6 & 5.4 \\
\hline Using or getting to toilet & $\mathrm{b}$ & $\mathrm{b}$ & 16.0 & 9.3 \\
\hline Eating & $\mathrm{b}$ & $\mathrm{b}$ & 13.1 & 8.7 \\
\hline Bathing and showering & $\mathrm{b}$ & $\mathrm{b}$ & 32.7 & 17.4 \\
\hline Dressing & $\mathrm{b}$ & $\mathrm{b}$ & 31.4 & 16.8 \\
\hline \multicolumn{5}{|l|}{ Disability Affects Ability to Do Things - } \\
\hline A great deal & 36.4 & 33.7 & 38.2 & 35.0 \\
\hline Some & 41.4 & 40.5 & 43.0 & 38.9 \\
\hline Very little & 18.8 & 20.8 & 16.6 & 21.6 \\
\hline No disability reported & 2.1 & 3.7 & 1.1 & 2.8 \\
\hline \multicolumn{5}{|l|}{ General Health Status } \\
\hline Poor & 9.1 & 8.3 & 9.2 & 9.3 \\
\hline Fair & 30.1 & 31.3 & 30.0 & 29.3 \\
\hline Good & 33.5 & 34.2 & 32.1 & 35.5 \\
\hline Very good & 15.6 & 17.5 & 15.5 & 14.4 \\
\hline Excellent & 11.5 & 8.5 & 12.8 & 11.0 \\
\hline \multicolumn{5}{|l|}{ Number of Hospitalizations in Previous 12 Months } \\
\hline Zero & 81.4 & 68.6 & 84.0 & 85.4 \\
\hline One & 7.9 & 11.6 & 7.1 & 6.7 \\
\hline Two & 3.7 & 6.0 & 3.8 & 1.8 \\
\hline Three or more & 6.4 & 12.6 & 4.9 & 5.1 \\
\hline
\end{tabular}

and extent of the child's disabilities, health problems, and patterns of health care utilization that are somewhat indicative of the severity of health problems. The data confirm that high proportions of SSI youth experience disabilities and health problems that are suggestive of substantial barriers to human capital development, but they are far from homogeneous. The extent to which family and public programs can alleviate these barriers 
Table 1, continued

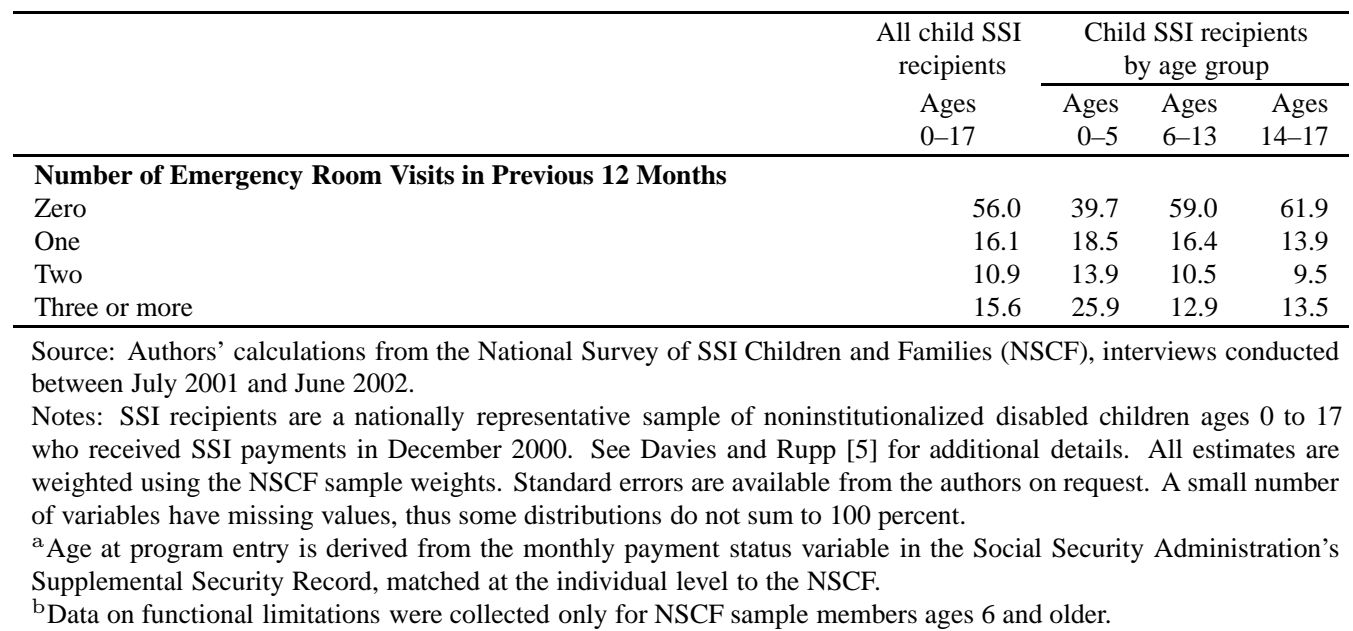

affects the challenges that employment-oriented transition programs will face in serving SSI youth into early adulthood. To address these heterogeneous needs, employment counselors and others likely will need to customize their approaches to a child's specific needs, rather than pursuing "one-size-fits-all" approaches. Individualized attention might help SSI youth successfully transition to economic self-sufficiency in adulthood.

\subsection{Family inputs affecting human capital development}

Parental human capital affects the quantity and quality of caregiving to SSI youth. As Aron and Loprest [2] note, this is an important area that is not well understood. Parents serve an important function in human capital development as role models and advocates for children. These parental roles are especially important in the context of the complex needs of children with disabilities and a fractured and underfunded public program environment. Rupp and Ressler ([23], this issue) fill some of this gap by addressing parental and family inputs to the human capital development of children, with a clear focus on family and nonfamily care.

Table 2 highlights some key aspects of the family environment for meeting the human capital development needs of children with disabilities, including both challenges and opportunities. The key challenges include single parenthood (limiting the total parental time budget available to attend to a child's needs), the presence of other children in the family (putting pressure on the parental time budget), and the presence of other family members with a disability. The latter is positively associated with the age of a child. The presence of other people with disabilities in the family might represent competing needs (for example, another child needing attention) and might affect the quantity and nature of parental inputs if a parent is disabled as well, as is the case for 15-20 percent of SSI youth ([23] this issue). Parental education has profound effects on almost every aspect of a child's human capital development in light of the complex challenges facing children with disabilities. Rupp and Ressler ([23] this issue) find that more than one-third of parents of SSI youth have less than a high school education. This is particularly problematic given that the quality and quantity of time spent with children tends to decrease if parents have less education [11]. Opportunities for a positive impact of the family environment on the human capital development of SSI youth include the presence of both parents (almost a third of all children), a grandparent, older sibling, or other relatives. A parent who is not working due to serious disabilities might be able to help his or her SSI recipient child to navigate the maze of programs and support services based on his or her own experiences. Some SSI youth have parents with relatively high levels of education, and these parents might be more effective in responding to a variety of a child's needs, such as advocacy and assistance in catching up after time lost at school.

Table 2 also describes the family environment in terms of parental earnings, poverty status, and assets. Parental employment and earnings affect both the resources available to pay for services needed by a child and the modeling of successful (or unsuccessful) adult labor market participation. About 40 percent of family income comes from the earnings of parents or guardians. Many child SSI recipients (44 percent) live 
Table 2

Characteristics of family environment of children receiving SSI in December 2000, by age group

\begin{tabular}{|c|c|c|c|c|}
\hline & \multirow{3}{*}{$\begin{array}{c}\text { All child SSI } \\
\text { recipients } \\
\text { Ages } \\
0-17\end{array}$} & \multicolumn{3}{|c|}{$\begin{array}{c}\text { Child SSI recipients } \\
\text { by age group }\end{array}$} \\
\hline & & Ages & Ages & Ages \\
\hline & & $0-5$ & $6-13$ & $14-17$ \\
\hline \multicolumn{5}{|l|}{ Sample Size } \\
\hline Weighted N & 791,954 & 154,492 & 421,629 & 215,834 \\
\hline Percentage (Weighted) & 100.0 & 19.5 & 53.2 & 27.3 \\
\hline \multicolumn{5}{|l|}{ Living Arrangements } \\
\hline Two-parent family & 29.3 & 37.3 & 28.7 & 24.5 \\
\hline Single-mother family & 56.3 & 56.6 & 57.4 & 53.7 \\
\hline Single-father family & 2.4 & $\mathrm{a}$ & $\mathrm{a}$ & 3.6 \\
\hline Family headed by other relative & 9.9 & 5.5 & 10.2 & 12.4 \\
\hline Other & 1.7 & $\mathrm{a}$ & $\mathrm{a}$ & 4.8 \\
\hline \multicolumn{5}{|l|}{ Number Under Age 18 in Household } \\
\hline One & 22.6 & 23.6 & 18.5 & 30.0 \\
\hline Two & 30.2 & 34.6 & 29.3 & 28.8 \\
\hline Three & 23.8 & 22.6 & 26.2 & 19.9 \\
\hline Four & 11.6 & 10.9 & 12.5 & 10.2 \\
\hline Five or more & 10.2 & 7.2 & 12.3 & 8.3 \\
\hline Percentage with Other Household Members with Disability & 48.9 & 38.3 & 51.1 & 52.3 \\
\hline Percentage with Any Parental Earnings & 54.5 & 57.7 & 56.1 & 49.3 \\
\hline Share of Family Income from Parental Earnings & 38.6 & 41.8 & 39.2 & 34.8 \\
\hline \multicolumn{5}{|l|}{ Total Liquid Assets of Parent or Guardian (dollars) } \\
\hline 0 & 39.1 & 38.4 & 39.3 & 39.3 \\
\hline $1-499$ & 34.8 & 34.1 & 35.0 & 35.1 \\
\hline $500-999$ & 6.9 & 7.6 & 6.9 & 6.2 \\
\hline $1,000-2,999$ & 10.4 & 10.2 & 10.7 & 9.9 \\
\hline 3,000 or more & 8.8 & 9.8 & 8.1 & 9.5 \\
\hline \multicolumn{5}{|l|}{ Total Debt of Parent or Guardian (dollars) } \\
\hline 0 & 50.0 & 43.5 & 51.3 & 52.2 \\
\hline $1-500$ & 5.9 & 6.2 & 5.7 & 6.2 \\
\hline $501-1000$ & 6.9 & 7.7 & 7.3 & 5.5 \\
\hline $1,001-5,000$ & 18.4 & 23.5 & 17.1 & 17.3 \\
\hline $5,001-10,000$ & 9.7 & 10.2 & 9.6 & 9.4 \\
\hline 10,001 or more & 9.1 & 8.9 & 9.0 & 9.5 \\
\hline \multicolumn{5}{|l|}{ Assets Owned by Parent or Guardian } \\
\hline Home & 36.0 & 36.2 & 35.9 & 36.1 \\
\hline Vehicle & 61.6 & 63.7 & 61.8 & 59.7 \\
\hline Checking account & 36.6 & 35.8 & 36.8 & 36.8 \\
\hline
\end{tabular}

Source: Authors' calculations from the National Survey of SSI Children and Families (NSCF), interviews conducted between July 2001 and June 2002.

Notes: SSI recipients are a nationally representative sample of noninstitutionalized disabled children ages 0 to 17 who received SSI payments in December 2000. See Davies and Rupp [5] for additional details. All estimates are weighted using the NSCF sample weights. Standard errors are available from the authors on request. A small number of variables had missing values, thus some distributions do not sum to 100 percent.

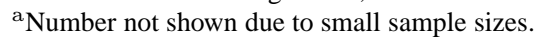

in families whose incomes are below the poverty level, which is expected given the program's income requirements. We note, however, that a substantially higher portion would be poor without access to SSI. Duggan and Kearney [8] show that SSI is highly effective in reducing poverty. Table 2 also presents indicators of family assets, which are relevant for a child's human capital development directly and in more subtle ways. For example, access to a vehicle helps to get a child to service providers, while home ownership is often associated with stability and emotional security. Par- ents with a checking account might be more effective in modeling financial management skills than parents who do not have checking accounts.

\subsection{Public inputs affecting human capital development}

As noted earlier, SSI youth face the dual challenges presented by their disabilities and factors associated with living in a poor or near-poor family. For public programs to be successful in countering the resulting 
Table 3

Public programs and benefits of children receiving SSI in December 2000, by age group

\begin{tabular}{|c|c|c|c|c|}
\hline & \multirow{3}{*}{$\begin{array}{c}\text { All child SSI } \\
\text { recipients } \\
\text { Ages } \\
0-17\end{array}$} & \multicolumn{3}{|c|}{$\begin{array}{l}\text { Child SSI recipients } \\
\text { by age group }\end{array}$} \\
\hline & & Ages & Ages & Ages \\
\hline & & $0-5$ & $6-13$ & $14-17$ \\
\hline \multicolumn{5}{|l|}{ Sample Size } \\
\hline Weighted $\mathrm{N}$ & 791,954 & 154,492 & 421,629 & 215,834 \\
\hline Percent (Weighted) & 100.0 & 19.5 & 53.2 & 27.3 \\
\hline Percentage ever received special education services & 69.1 & 38.1 & 76.2 & 77.5 \\
\hline Percentage ever had an individual education plan & 67.7 & 41.5 & 76.3 & 69.8 \\
\hline \multicolumn{5}{|l|}{ Health Insurance Coverage } \\
\hline Percentage with any health insurance coverage & 98.3 & 98.6 & 98.6 & 97.5 \\
\hline Percentage with Medicaid coverage & 90.4 & 90.1 & 90.5 & 90.5 \\
\hline Percentage with coverage through the State Children's Health Insurance program & 14.0 & 15.7 & 14.1 & 12.7 \\
\hline Share of Family Income from SSI & 47.7 & 46.0 & 47.2 & 49.9 \\
\hline \multicolumn{5}{|l|}{ In-Kind Transfers of Family } \\
\hline Percentage receiving food stamps & 31.1 & 36.6 & 30.2 & 29.0 \\
\hline Mean monthly amount of food stamps among recipients & $\$ 235.52$ & $\$ 234.74$ & $\$ 244.7$ & $\$ 217.57$ \\
\hline Percentage receiving housing assistance & 18.5 & 17.2 & 18.9 & 18.6 \\
\hline Percentage receiving energy assistance & 19.3 & 17.2 & 20.2 & 19.0 \\
\hline
\end{tabular}

Source: Authors' calculations from the National Survey of SSI Children and Families (NSCF), interviews conducted between July 2001 and June 2002.

Notes: SSI recipients are a nationally representative sample of noninstitutionalized disabled children ages 0 to 17 who received SSI payments in December 2000. See Davies and Rupp [5] for additional details. All estimates are weighted using the NSCF sample weights. Standard errors are available from the authors on request.

${ }^{a}$ Medical out-of-pocket expenses include out-of-pocket expenses for physical health care (including doctor visits, hospital stays, and prescription drugs) and mental health and substance abuse treatment (including both inpatient and outpatient care) in the previous 12 months, as well as out-of-pocket expenditures for all services or equipment in the past 12 months (including physical, occupational, or speech therapy; respiratory therapy; recreational therapy; audiology therapy; transportation services; respite care; mental health counseling; and durable medical devices). This is a broader definition than the definition used by DeCesaro and Hemmeter ([6], this volume). Thus, we report a higher percentage of SSI children with medical out-of-pocket expenses.

${ }^{\mathrm{b}}$ Data on SSI are restricted to families reporting SSI receipt. Although the sample was drawn from the population of children receiving SSI, 7 percent reported that they were no longer receiving SSI income support at the time they were interviewed. The distribution for this variable was limited to the remaining 93 percent of the observations.

long-term challenges of human capital development, resources need to be devoted to address both, rather than one or the other in isolation. This is a tall order, and provides a strong justification for targeting public resources to the SSI target population of youth with disabilities in families with limited means. Indeed, one of the justifications for the SSI program for children is that children with severe disabilities often have special needs that result in extra burdens on family time and expenditures. Likewise, the categorical eligibility of SSI youth for other programs is justified by their extra service needs. In this subsection, we provide a broad outline of the major public programs serving youth with disabilities. The interested reader is referred to Aron, Loprest, and Steuerle [1] for a systematic discussion. In the discussion below, we present some basic indicators of three major groups of public programs that are important in serving the needs of SSI youth: (1) education programs, (2) health insurance, and (3) cash benefit and targeted subsidy programs. Of these three, education programs are the most transparently relevant for human capital development, but there is ample evidence demonstrating the importance of the other two groups of programs in countering the negative effects of poverty and meeting the service needs of children with disabilities.

\subsubsection{Education}

Since the pioneering work of Nobel Laureate Gary Becker at the University of Chicago and Professor Jacob Mincer at Columbia University several decades ago, a substantial body of literature has demonstrated the importance of education in human capital development. The public education system clearly is highly relevant for children with disabilities from first grade 
to high school completion and beyond; relevancy is increasingly expanding to the preschool years. The largest educational program for children with disabilities is special education, reflecting the need of many children with disabilities to resolve a variety of challenges in school. Children with intellectual disabilities may improve their school performance dramatically with intensive supports. Some children with physical disabilities need assistive devices; others need assistance in addressing time lost from school (through hospital and home instruction and other accommodations in daily schedules, tests, and curriculum). Aron and Loprest [2] provide an overview of the educational support system for children with disabilities. Failure of support systems in any area might result in children with disabilities failing grades, dropping out of school, and not acquiring basic skills that are needed to facilitate a successful transition to adulthood. Wittenburg and Loprest [34], using data from the NSCF, document the relatively high prevalence among SSI youth ages 14 to 17 of problems at school and other serious problems, such as involvement with the criminal justice system.

Table 3 provides several indicators of participation in school and in major programs that are designed to assist children and young adults with special needs. A substantial portion of preschool-aged children on SSI participate in early childhood education; school enrollment reaches almost 100 percent in the 6 to 13 age group, but drops during the high school years. Many youth can qualify for specialized supports while they are in school under the Individuals with Disabilities Education Act (IDEA), which requires schools to provide special education and related services to students with a wide range of impairments. Indeed, more than twothirds of SSI youth have been involved in special education at some point in their lives. A similar proportion has ever had an individual education plan.

\subsubsection{Health}

A large body of literature demonstrates the usefulness of applying the human capital model to health, dating back to the pioneering work of Michael Grossman during the early 1970s. According to this perspective, health is a durable capital stock that yields an output of healthy time. People inherit a certain amount of this stock that depreciates with age and unexpected health shocks and can be increased by investment. Investments in health and access to health insurance are especially important for SSI youth from a long-term human capital accumulation perspective. Public health insurance is critical in countering the lack of private health insurance for the vast majority of the families of SSI youth and the limited parental resources that might be available to purchase unsubsidized health care, supportive services, and therapies in the private market. As shown in Table 3, Medicaid is primarily responsible for the nearly universal health insurance coverage of children on SSI, which is not surprising given the categorical links between Medicaid and SSI. Due in part to public health insurance through Medicaid, fewer than one-third of SSI youth report out-of-pocket expenses for medical care, with more out-of-pocket expenses occurring for younger SSI recipients (ages 0 to 5). These findings are consistent with those reported by $\mathrm{DeCe}-$ saro and Hemmeter ([6], this issue), who conduct a detailed analysis of the medical out-of-pocket expenses and unmet health care needs of SSI youth.

\subsubsection{Cash benefits and targeted subsidies}

SSI is a cash benefit and provides an opportunity for parents to purchase goods and services, including some that might contribute to the human capital development of a child. ${ }^{1}$ Food stamps are an in-kind transfer. For some families with very limited resources, food stamps may provide a net benefit to the nutritional status of an SSI child rather than substituting for other sources of income that would be used to pay for food in the absence of food stamps. The importance of government-provided housing and energy assistance is twofold. First, they directly influence the quality of a child's home environment. Second, these subsidies may substitute for cash that could be spent for other purposes, including goods or services contributing to an SSI child's human capital development. The bottom portion of Table 3 presents indicators of cash benefits, cash-like benefits, and subsidies that are relevant in terms of providing more or less liquid resources for the families of SSI recipient children. On average, almost half of the income for families of children with disabilities comes from SSI. The cash value of food stamp benefits is also nontrivial ( $\$ 235.52$ per month among families of SSI children that receive food stamps), though only 31 percent of the families of SSI youth receive

\footnotetext{
${ }^{1}$ DeCesaro and Hemmeter ([6], this issue) analyzed questions on the NSCF about what a family would do if its monthly income increased or decreased by $\$ 100$. The most common responses were to spend more on food, personal items, and debt reduction if monthly income increased by $\$ 100$, and to spend less on everything, personal items, other expenses, and food if monthly income decreased by $\$ 100$. Few respondents indicated that they would spend more (cut back) on disability-related expenses if their monthly income increased (decreased).
} 
these benefits. Government-provided housing and energy assistance also contribute to family expenditures in some cases (each less than 20 percent).

\subsubsection{Unique challenges facing transition-age youth}

As youths move from childhood into their late teen years, their family, social, and school context all can change, including greater independence to make decisions that could affect their long-term human capital development through schooling, employment, and training. Transition-age youth on SSI face special challenges due to the severity of their disabilities, limited resources, and the potential changes to SSI eligibility and the SSI benefit amount resulting from the age-18 redetermination process. Their limited family incomes and potentially costly health care needs might limit the ability of many SSI youth to participate fully in activities relative to other youth. On the other hand, the SSI program offers many features to encourage the human capital development of SSI youth. For example, Section 301 of the Social Security Disability Amendments of 1980 (P.L. 96-265) allows a former SSI recipient who was enrolled in an approved vocational rehabilitation program prior to his 18th birthday to keep his SSI (and DI) cash benefit while he works on his vocational goals. The former SSI recipient also may keep his Medicaid benefits in most states while still a client of vocational rehabilitation. Other work incentives, such as the earned income exclusion, the student earned income exclusion, and the impairment related work expense provisions also help SSI youth maintain a minimum income level as they begin to work as young adults [31].

Currently, many SSI youth experience relatively poor human capital and social outcomes as they move into young adulthood. According to Loprest and Wittenburg [15], 39 percent of youth ages 19 to 23 who previously received child SSI benefits had dropped out of school and only 21 percent were employed. A bigger concern was that approximately one-fifth of these youth had been arrested and most (57 percent) did not participate in any school, vocational rehabilitation program, or employment activity. The relatively limited human capital stock and social outcomes for SSI youth have important implications for their ability to become self-sufficient adults. Because most young adults who received SSI benefits as children are not investing in their human capital through work, rehabilitation, or education for a variety of reasons, they are at high risk for a lifetime of reliance on disability benefits and Medicaid. Some have disabilities so severe that they might need ongoing long-term supports through SSI and other programs, often for a lifetime; others may benefit from interventions oriented toward human capital development. The social development of some young adults has been limited, which might result in social isolation and involvement with the legal system in the short run; in the long run it might further increase the risk of reliance on SSI. Hemmeter, Kauff, and Wittenburg ([12], this issue) find that nonhealth factors, particularly education, employment, and social indicators, play an important role in the probability of an SSI youth being on SSI as an adult after age 18. They also show that the transition experience varies substantially across impairment subgroups.

Over the past 20 years, SSA has conducted three random assignment demonstrations to test the efficacy of various strategies to help disability applicants and beneficiaries transition to productive employment and reduce their dependence on disability benefits. These demonstrations varied in the extent to which they provided services to young adults. The Transitional Employment Training Demonstration (TETD) (1985-1987) provided time-limited job placement services and on-the-job training to SSI recipients ages 18 to 40 with mental retardation. Project Network (19921994) tested various approaches to providing case management and targeted a broader range of DI and SSI disability beneficiaries and SSI applicants, with extra outreach to youth ages 18 to 24. The State Partnership Initiative (SPI) (1999-2004) provided a limited set of employment and benefit counseling supports for SSI recipients. ${ }^{2}$ Although some young adults were included in the demonstrations, most participants were on the disability rolls well into adulthood at the time of enrollment in the assistance programs tested. The somewhat disappointing results of these demonstrations led to the search for new strategies.

One of the promising new strategies was to shift the focus of assistance to earlier in the life cycle, before adult patterns of employment and reliance on benefits are settled. This innovative strategy set the stage for new SSA demonstration initiatives, including the new YTD project that is described extensively in this issue.

\footnotetext{
${ }^{2}$ A summary of these demonstrations is available in Rangarajan, Wittenburg, Honeycutt, and Brucker [19]. The six-year results of TETD were presented by Decker and Thornton [7]. Initial net impact results from Project NetWork were summarized by Kornfeld and Rupp [14]; Rupp and Bell [22] provided six-year estimates of earnings and benefit receipt for DI beneficiaries who participated in Project NetWork. The impact findings for the SPI projects were presented in Peikes et al. [18].
} 
As noted in Fraker and Rangarajan ([10], this issue), SSA initiated YTD to assist youth in making human capital decisions during the critical years of transition to adulthood. The goal is to make improvements in the employment and program outcomes of youth who are on or at risk of receiving SSA disability benefits. SSA is investing considerable resources in YTD, which offers key transition services to large numbers of youth with disabilities to help alleviate the barriers they face in their current service environments. The YTD initiative includes a set of SSA waivers of disability program rules that encourage youth to work by allowing them to retain more benefits as their earnings increase.

Although it is unlikely that YTD will result in a large reduction in the caseload, it can nonetheless be cost effective if even a small number of youth reduce their dependency on benefits. Historically, a substantial share of SSI youth participates in SSI long into adulthood (see [24]; and section 4 of this paper). Fraker and Rangarajan ([10], this issue) show that even a small reduction in the caseload would result in a large return in benefit savings. Additionally, the YTD interventions can have effects on the use of other government services (such as the juvenile justice system) that could make these programs cost beneficial from a social standpoint. Perhaps most importantly, the combination of intensive services and strong work incentives (SSA waivers) has the potential of increasing long-term employment and earnings more than was achieved through the previous SSA demonstrations. ${ }^{3}$

\section{Longer-term outcomes}

In this section we provide some evidence on longerterm outcomes in terms of SSI program participation and earnings patterns of individuals who first received SSI as children. Our goal is to present a first look at patterns of long-term SSI participation and earnings

\footnotetext{
${ }^{3}$ One of the interesting questions involves the potential trade-offs between social benefits and government expenditures. Strong work incentive waivers are arguably necessary to achieve substantial earnings impacts. The flip side is that strong waivers allow disability beneficiaries to stay on the rolls even if they succeed in transitioning to substantial employment. Thus, at least in the short run, it is entirely possible that positive net earnings results are associated with negative net caseload effects in terms of failure to reduce reliance on SSI benefits. The hope is, of course, that in the long run sustained positive earnings impacts will reduce reliance on disability benefits and will lead to reductions in costly adverse social outcomes, such as imprisonment. This is one reason we will need some patience in making a final assessment about the promises of the YTD intervention.
}

across child SSI award cohorts and by age at award. The findings to follow provide a context for the longterm outcomes of child SSI awardees and how they change over time.

Using SSA administrative data from the Supplemental Security Record, we identify all children who were first awarded SSI benefits in 1980 and 1997. ${ }^{4}$ Year of award is based on the month and year in which an individual first received an SSI payment. We then longitudinally track SSI participation for the children in each award cohort through early 2008. Receipt of SSI is measured by SSI payment eligibility status in January of a given year. This measure ignores shortterm (monthly) caseload dynamics, reflecting a reasonable simplifying assumption in the present context. We track annual earnings in Social Security-covered employment from SSA's Master Earnings File for the children in each award cohort through 2007, the latest year for which we have data.

In both the SSI participation and the earnings analyses, we track all awardees - those who remain on the program as well as those who are not on SSI for a variety of reasons, including death. Including all awardees in the longitudinal analysis gives us a full picture of the percentage of initial childhood awardees who received benefits at any later point in time, as well as the percentage that had earnings during a given year. We discuss reasons for SSI exits later, but note that death is a relatively infrequent event among childhood awardees. ${ }^{5}$

\footnotetext{
${ }^{4}$ We also analyzed the 1985, 1990, 1995, and 2000 SSI child award cohorts. However, to simplify the presentation we show only the 1980 and 1997 cohorts here. Based on our inspection of the data for all six award cohorts, we established that there is a clear structural shift between the 1990 and 1995 award cohorts, and that the 1980 award cohort is representative of early experience while the 1997 cohort is representative of more recent experience. The statistics presented in this section are based on population data for the nearly 600,000 individuals who make up the six awardee cohorts. Because we use population data, standard errors are unnecessary for our descriptive analysis.

${ }^{5}$ Rupp and Scott [24] estimates that fewer than 7 percent of childhood awardees completed their first SSI spell due to death during the first 10 years after initial award. Our calculations based on SSA [27] indicate that death as a reason for termination hovered between 0.4 percent and 0.6 percent of the childhood caseload annually between 1999 and 2007. This annual exit rate for death is dwarfed in comparison with terminations for other reasons. Another indicator of caseload dynamics, suspensions, shows even greater contrast with death as a reason for exit among children on SSI. See SSA [29] for statistics on suspensions during the same time period. Note that the estimates by Rupp and Scott [24] based on award cohorts are more directly comparable to our data than these other statistics, which express the flow of annual exits relative to the caseload.
} 
In the discussion that follows, we present SSI participation and earnings outcomes for each award cohort for children ages $0,6,13$, and 17 at first SSI award. These ages represent children who first entered SSI at birth, first grade in elementary school, middle-school, and high-school, respectively, and thus reflect awards at distinct points in the childhood portion of the life cycle. Age at award is measured as the difference between the month and year of the first SSI payment and the month and year of birth. Age in the final year of our observation period (2008 for SSI receipt, 2007 for earnings) is the age the individual will attain in that calendar year. Children age 0 at award include low birth weight babies, a unique category of childhood awardees because of the mandatory continuing disability review for most such cases by age 1 . For the oldest awardees in our data (1980 award cohort, age 17 at award), we observe SSI participation and earnings through ages 45 and 44 , respectively. For the 1997 award cohort, we observe SSI participation and earnings into the late teenage and early adulthood years.

Figure 1a-1d show the percentage receiving SSI by age for the two award cohorts and four ages at award. Several patterns immediately emerge. First, the percentage receiving SSI declines rather quickly in the five years after award for all cohorts and all ages at award. Looking first at the 1980 award cohort, we observe that the rate of decline is clearly faster during the first five years for the two younger age-at-award groups (ages 0 and 6 at award) than for the older groups (ages 13 and 17) - roughly 30 to 50 percent among younger awardees, compared with about 20 percent for the older groups. Interestingly, after this five-year drop in participation, across all age groups we find that longerterm participation rates drop much more slowly; people who stay on the roles for five or more years might be more likely to become very long-term SSI participants. Second, when we look at longer-term participation patterns in adulthood, we also observe a greater drop in participation among younger awardees. For example, looking at participation at age 28 for the four age-ataward groups, we find roughly 70 percent and 40 percent attrition for the younger two groups, compared with about 30 percent attrition for the older two groups. Undoubtedly the length of exposure between award and age 28 affects these patterns. Finally, there is a tendency for a larger drop in SSI participation across the age-at-award spectrum among the 1997 award cohort. For example, among those age 17 at award, the decline in SSI participation was roughly 40 percent of that of the 1997 cohort, compared with roughly 20 percent of the 1980 award cohort. These patterns are remarkable, but more research needs to be done to understand the role of various correlates.

We have not explicitly explored reasons for SSI exits, though past research suggests that exits based on excess income appear to be a major driver. Rupp and Scott [24] found that 36 percent of SSI awardees between 1974 and 1982 who were ages 0 to 17 at award stayed continuously on the rolls (had no exit from the rolls) for at least 10 years after first award. Excess income was the primary reason for first exits, accounting for more than one-third of all childhood awardees. In other words, among the two-thirds of SSI awardees who exited the rolls, roughly half exited due to excess income. Adding those who left due to excess resources increases the proportion that left because of the SSI means test. As noted before, a relatively low proportion left the rolls due to death. SSI statistics for 1999 to 2007 also support the importance of exits due to the means test, showing that suspensions attributable to excess income and/or resources amounted to 50-60 percent of all childhood suspensions ([29]; authors' calculations). ${ }^{6}$ All in all, past research suggests the importance of exits from SSI due to the SSI means test, both prior to and after the 1996 welfare reform legislation (P.L. 104-193). The role of other factors, such as the extent of continuing disability reviews and legislation, has varied over time. For example, previous work provides credible evidence of a reduction in the childhood SSI caseload attributable to the welfare reform legislation, at least in the short run $[13,20]$. In addition, the percentage of terminations for reasons other than death among SSI youth jumped from 5 percent of the caseload in 1996 to a high of 15 percent in 1997, but fell back to 5 percent by 2006 ([27]; authors' calculations).

Although the percentage receiving SSI in each award cohort drops off relatively quickly with time since award, by the end of our observation period a substantial fraction of each award cohort receives SSI. Depending on the award cohort and age at award, roughly

\footnotetext{
${ }^{6}$ Another piece of evidence that suggests a role for the SSI means test is provided by the clear uptick in the percentage receiving SSI at age 18 among those who entered SSI at ages 0,6 , and 13 from the 1980 award cohort. A plausible hypothesis is that children under age 18 might lose eligibility due to parental deeming (for example, parent's earnings), whereas a child may qualify again as an adult when deeming no longer applies after the 18 th birthday. The evidence is limited for the 1997 award cohort, but the lack of a comparable uptick around age 18 in the percentage receiving SSI among those age 13 at award in 1997 suggests a structural shift that might be associated with the age- 18 redetermination provisions of the 1996 welfare reform legislation.
} 


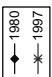

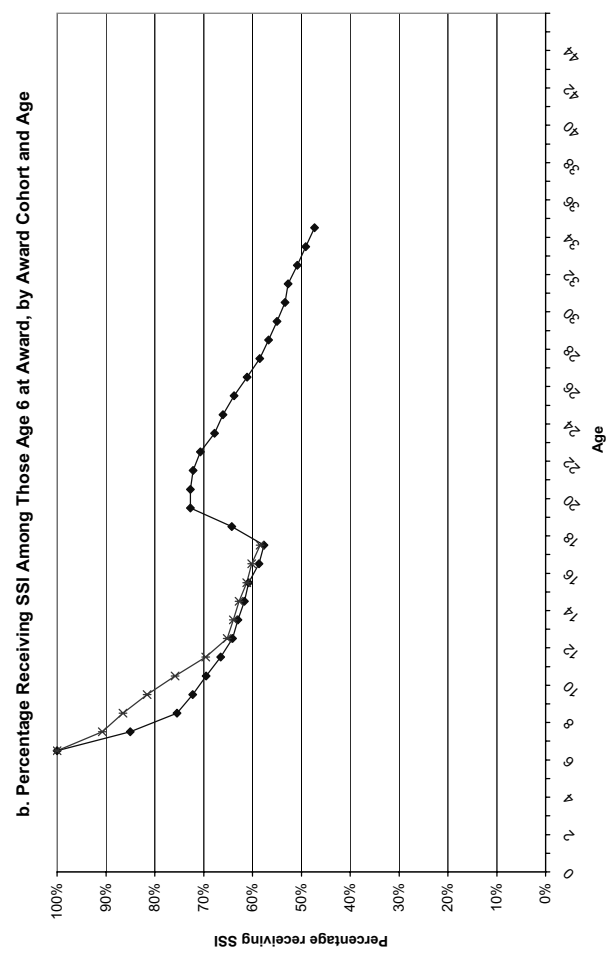

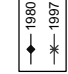

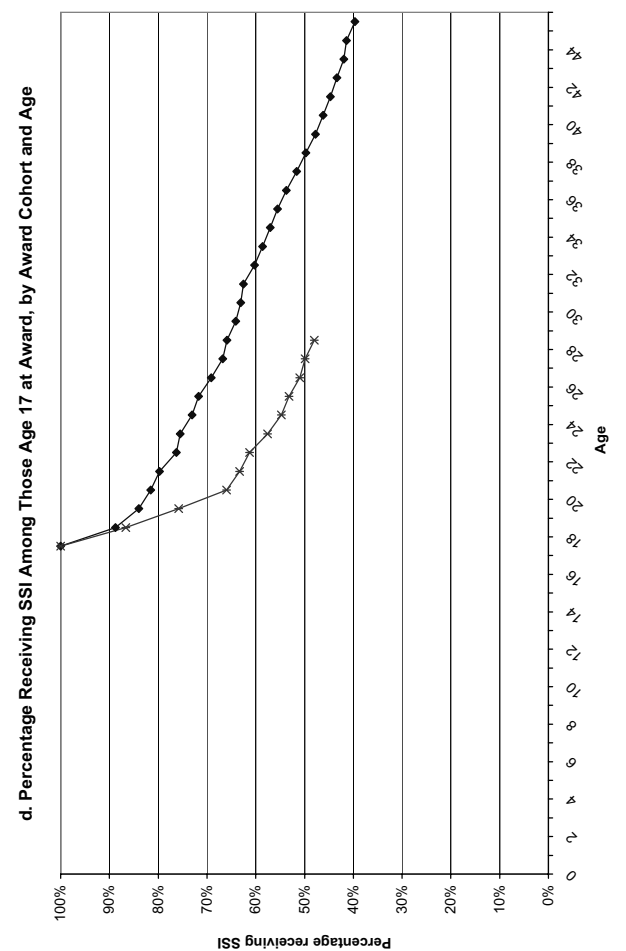

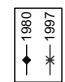

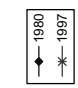
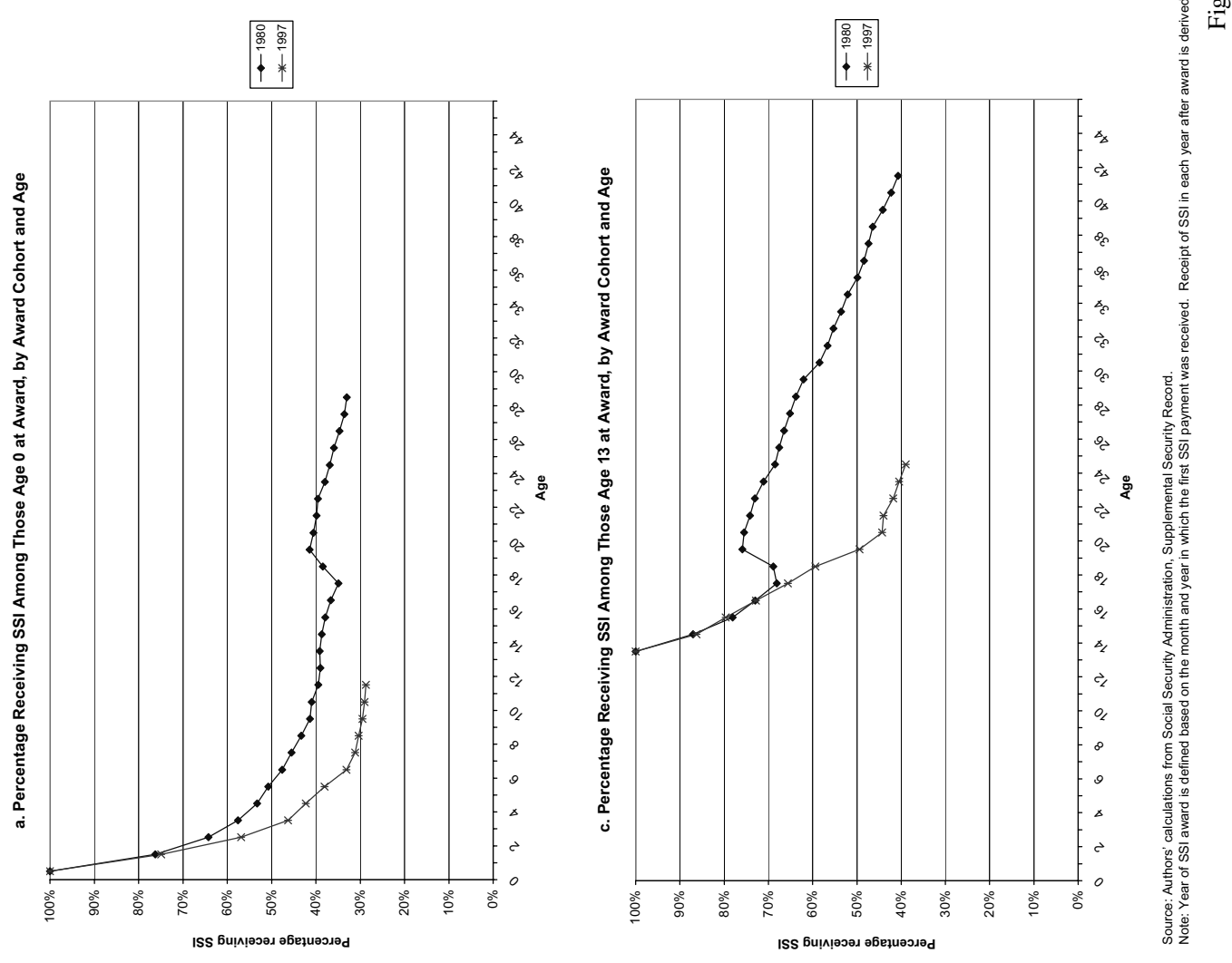
30-50 percent of awardees receive SSI benefits at the last observation point in Fig. 1a-1d. We observe those age 17 at award from the 1980 award cohort well into adulthood. The data display a monotonic decrease in the rate of participation, reaching 40 percent at age 45 , suggesting that long-term or even lifetime reliance on SSI benefits is a very real possibility for many. Indeed, Rupp and Scott [24] estimate that the mean duration on SSI (including multiple spells) among those who first received benefits as children between 1974 and 1982 is about 27 years prior to reaching age 65 . Our data suggest that the trends may have shifted toward more rapid reduction in participation - and hence shorter lifetime duration on SSI - since the mid 1990s.

Figure $2 \mathrm{a}-2 \mathrm{~d}$ show the percentage of awardees with earnings at ages 15 and older. Each chart represents a different age at award $(0,6,13$, and 17). These charts are derived from administrative earnings records, but the presence of any earnings can be interpreted as a measure of any employment during the year, a relatively generous measure of employment. The charts generally show that the percentage with earnings grows rapidly during the late teen years as children begin the transition to adulthood. The more recent SSI award cohorts experience more rapid growth in the percentage with earnings, consistent with the more rapid decline in SSI participation among the more recent award cohorts, as noted above.

Although labor force entry is occurring among these child SSI awardees during the late teen years, the rate of employment seems to peak during the early to middle 20s for the 1980 award cohort and slowly declines thereafter until about age 45, the latest observation point in our data. This is particularly true for those who first received SSI at younger ages, suggesting that age at award is negatively associated with lifetime employment, although exits due to death need to be considered before a firm conclusion is reached. Nevertheless, the salient point is that employment levels are fairly low through most of early and middle adulthood. Turning our attention now to the 1997 entry cohort, we highlight two points. First, we have fewer observation points. Second, the age-employment profile for those ages 13 and 17 at award shows an unambiguous upward shift compared with the earlier award cohort. It appears that positive earnings peak at about 50 percent around age 20, substantially higher than the 1980 cohort.

Finally, Table 4 shifts perspective and compares employment and earnings patterns for members of various SSI award cohorts in 2007. In addition, we include a comparison group of a representative sample of all members of the U.S. noninstitutional population in the same age groups in 2007 using the March 2008 Current Population Survey. The top panel of Table 4 shows that the percentage with positive earnings is higher for the 1995-2000 SSI award cohorts across all ages compared with the earlier cohorts. The comparison series for all members of the U.S. noninstitutional population in the given age groups in 2007 (first line) provides a gauge as to how youth who were awarded SSI benefits in childhood fare compared with the overall population in the same age group. Around 80 percent of all individuals have positive earnings across the 2007 age groups (first line); the corresponding averages are about 40 percent for SSI awardees, with considerable variation by award cohort.

The bottom panel of Table 4 contains data on average earnings conditional on the presence of any earnings. A few profound differences emerge. First, average earnings for all SSI award cohorts and age groups are consistently less than half of the average for all members of the noninstitutional population in the given age groups (first line). Second, for all members of the noninstitutional population represented by people ages 19 to 38 in 2007, average earnings increase across age groups, which is consistent with the general age-earnings profile in the United States population. In contrast, the age-earnings profile is flat and shows little variation across SSI award cohorts in the 24 to 38 age groups. Third, childhood SSI awardees are falling farther behind others in the noninstitutional population as they age. Finally, the average earnings of childhood SSI awardees tend to be well below the average earnings of a full-time, full-year worker at the minimum wage. These contrasts show that the challenges facing employment-oriented programs for transition-age SSI youth are even more substantial in the long run than in the short run; the data show no improvement in the work patterns of childhood SSI awardees past their mid-20s. One of the challenges for human capital interventions is to increase not only the portion who work, but the portion with meaningful earnings.

Taken as a whole, the longer-term results on the percentage who continue to receive SSI and the percentage with earnings are consistent with the discussion in the previous section of the special challenges facing SSI youth as they transition to adulthood. Because of the relatively poor human capital and social outcomes of SSI youth, a substantial fraction appears to be headed for a lifetime of reliance on SSI benefits and weak labor market outcomes. Yet the fact that a large fraction of SSI awardees eventually leaves the rolls, combined 

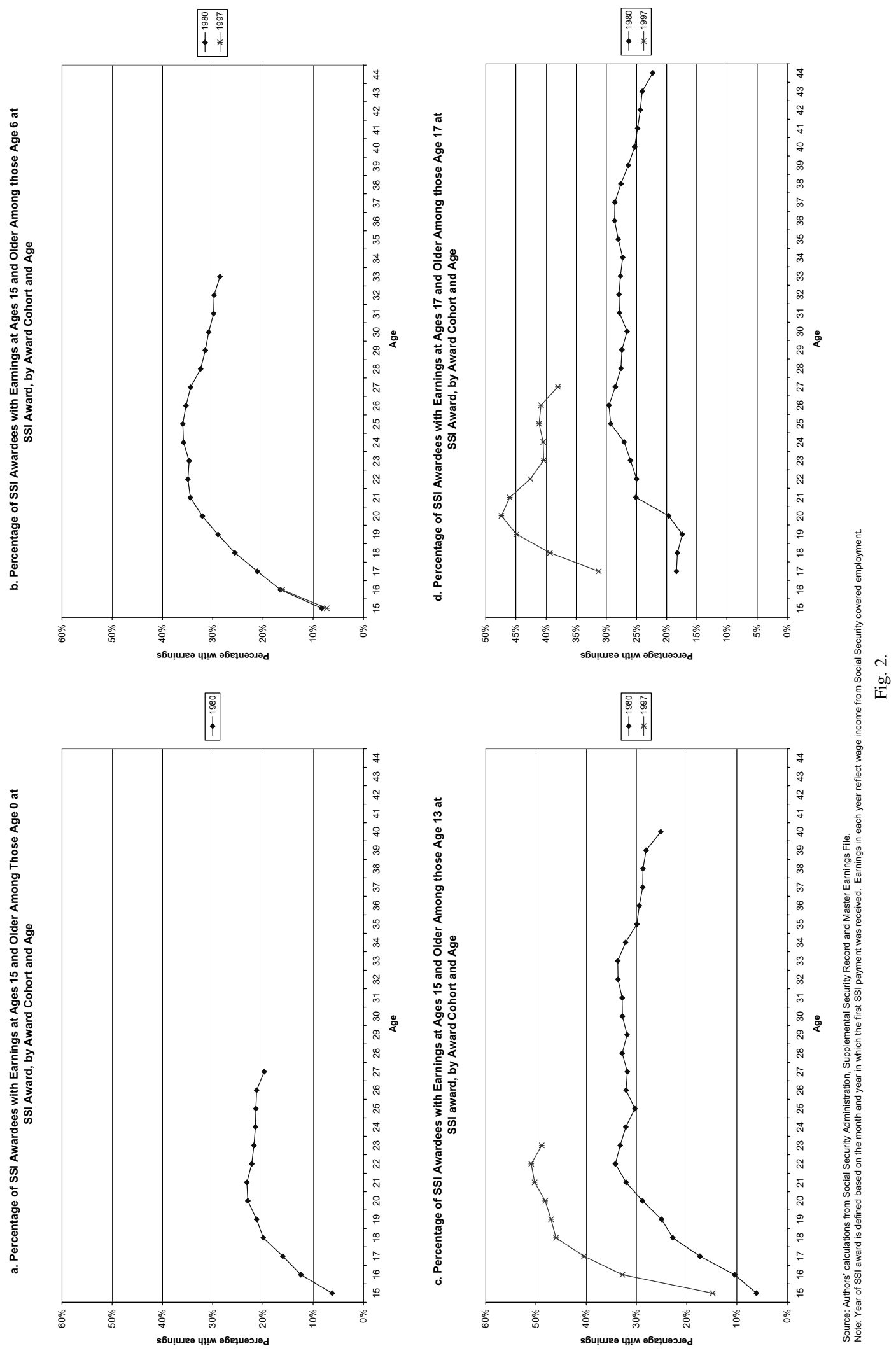
Table 4

Comparison of earnings in 2007 among SSI child awardees and all individuals in the U.S. noninstitutional population, by award cohort and age group in 2007

\begin{tabular}{|c|c|c|c|c|}
\hline \multirow[b]{2}{*}{ Outcome Variable and Subgroup } & \multicolumn{4}{|c|}{ Age in 2007} \\
\hline & $19-23$ & $24-28$ & $29-33$ & $34-38$ \\
\hline Presence of Earnings in 2007 & \multicolumn{4}{|c|}{ Percentage with Positive Earnings } \\
\hline All Individuals in U.S. Noninstitutional Population in $2007^{\mathrm{a}}$ & 77 & 84 & 84 & 84 \\
\hline \multicolumn{5}{|l|}{ SSI Awardees in Year: } \\
\hline 1980 & - & 20 & 28 & 28 \\
\hline 1985 & 23 & 32 & 33 & 30 \\
\hline 1990 & 36 & 40 & 36 & - \\
\hline 1995 & 51 & 48 & 40 & - \\
\hline 1997 & 48 & 44 & - & - \\
\hline 2000 & 47 & - & - & - \\
\hline Average 2007 Earnings Conditional on Presence of Positive Earnings & \multicolumn{4}{|c|}{ Average Earnings (2007 Dollars) } \\
\hline All Individuals in U.S. Noninstitutional Population in $2007^{\mathrm{a}}$ & 18,029 & 33,065 & 41,535 & 48,402 \\
\hline \multicolumn{5}{|l|}{ SSI Awardees in Year: } \\
\hline 1980 & - & 12,509 & 12,583 & 12,412 \\
\hline 1985 & 7,954 & 10,256 & 12,273 & 12,890 \\
\hline 1990 & 6,522 & 10,434 & 12,448 & - \\
\hline 1995 & 6,788 & 10,696 & 12,559 & - \\
\hline 1997 & 6,432 & 10,010 & - & - \\
\hline 2000 & 5,917 & - & - & - \\
\hline
\end{tabular}

Source: Estimates for SSI award cohorts are authors' calculations from Social Security Administration, Supplemental Security Record and Master Earnings File. Estimates for all individuals in the U.S. noninstitutional population in 2007 are authors' calculations from the March 2008 Current Population Survey public use file.

Notes: All individuals in the 19-23 age group transitioned to adulthood after 1997. The birth cohorts corresponding to the four age groups in 2007 are as follows:

age in 2007 birth cohort

$19-23 \Longrightarrow 1984-1988$

24-28 $\Longrightarrow 1979-1983$

$29-33 \Longrightarrow 1974-1978$

34-38 $\Longrightarrow 1969-1973$

Cell values of "-" indicate that SSI awardees in that age group and award cohort were not children (ages 17 or under) at the time of award.

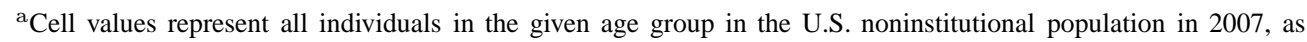
calculated from the March 2008 Current Population Survey.

with the finding that a nontrivial minority has positive earnings in early adulthood, suggests that carefully crafted and targeted interventions might bear fruit in the future. Additional research is necessary to understand the differences in SSI participation and employment across award cohorts. Perhaps the most obvious next steps are to identify reasons for exits from SSI and to consider other factors, such as type of disability. The papers in this issue, along with SSA's YTD project, provide a foundation for thinking about longer-term outcomes.

\section{Summary}

In this paper we developed a life-cycle perspective to illustrate the challenges and opportunities of human capital development among transition-age SSI recipients who were first awarded SSI benefits as children. Our descriptive comparisons provide background infor- mation on several factors influencing a youth's human capital development, including individual demographic and impairment characteristics, family influences, the SSI program, and other public programs and services (such as schools and other transfer programs). We also presented data from SSA administrative records to illustrate the long-term prospects of SSI youth for SSI benefit receipt and employment. Our findings illustrate the heterogeneous nature of the child SSI population and underscore the need that many child SSI recipients have for additional supports to make a successful transition to adulthood. The life-cycle perspective has important implications.

- There are some simple but profound implications for coordination among programs. Our findings suggest that there is substantial need to coordinate among programs and interventions focusing on children and youth of different ages. Proper design and navigation requires not only contemporaneous coordination, but also longitudinal coordi- 
nation, in which youth receive supports for several years to address ongoing issues. For example, coordination between vocational rehabilitation programs for transition-age youth and middle schoollevel special education could lead to enhancing the focus of special education programs on basic skills that are essential for successful labor force entry. This could help avoid the problem of vocational rehabilitation programs having to reteach basic skills that are customarily acquired earlier in life.

- Decisions made about the allocation of resources for various interventions need to consider the lifecycle context. At what stage of the life cycle or SSI participation is it best to intervene? Early childhood? Transition age? Programs focusing on children who are not yet on SSI or back-end interventions? SSA has had somewhat disappointing experiences with back-end interventions for adults (for example, assisting adults who have been on the disability rolls for several years); hence the recent push for front-end and transition-age interventions. The YTD is hopefully a step in the right direction, though additional supports might be necessary to serve youth at younger ages, particularly given that the majority of SSI youth enter the rolls prior to age 10 . Whether these alternatives will work better is an open question. There are a host of pros and cons in theory, a good reason for carefully designed evaluations. Substantial complementarity might exist among early childhood interventions designed to enhance health, to provide high-quality subsidized child care and early education, and employment-oriented interventions later in life.

- The life-cycle perspective is extremely important both for program design and evaluation. For example, although some interventions might look better than others in terms of short-term outcomes, the opposite might be true in the long run. Job search assistance might improve employment outcomes in the short run, but these effects might soon disappear. In contrast, improving educational and health outcomes through more intensive human capital investments might produce few or even negative effects in the short run (college education for young adults with disabilities), but might improve outcomes on a more sustained long-term basis. However, the net outcomes are influenced by a host of factors. Job search assistance in some cases may result in positive long-term outcomes at low cost. In contrast, poorly targeted and implemented education-oriented programs might be costly and fail to deliver positive long-term outcomes. Consequently, the evaluation of initiatives such as YTD needs to address both short- and long-term objectives.

The life-cycle human capital perspective provides a broader context of the challenges and opportunities for serving the needs of children with disabilities whose families have limited resources. Employmentoriented assistance for SSI recipients often faces a major challenge because it targets a population that has already qualified for benefits based on severity of disability. Assistance that focuses on employment might not meet the needs of all SSI youth with disabilities. Some might self-select out of employment-oriented programs, though these youth potentially need a host of other supports and services (such as impairmentspecific supports), sometimes for a very long time. The government and service providers face a difficult balancing act between the desire to target employmentoriented services to those more likely to benefit (which runs the risk of inappropriately denying services to some who need them), and the possibility of ineffective use of scarce resources on those who might succeed without services (the classical problem of cream skimming) or on others who might not benefit from costly employment assistance. Voluntary participation in the context of SSA's employment assistance initiatives is clearly appropriate in light of the pervasive screening problems and the fundamental principle of "do no harm." Employment-oriented voluntary service strategies also have the desirable property that they can be implemented without adverse effects on other beneficiaries (nonvolunteers). However, they place a burden on the taxpayer, at least in the short run, and if poorly implemented can be ineffective or excessively costly.

The remainder of this volume provides additional insights and evidence concerning various aspects of the human capital development of children and young adults on SSI. The first three papers to follow provide a more in-depth look at the characteristics, environment, needs, and activities of the child SSI population.

- Rupp and Ressler focus on family caregiving and employment among parents of child SSI recipients. Their paper illustrates how several youth and family characteristics might affect parental caregiving and employment decisions. They find that child SSI recipients who have severe disabilities and/or live in single-parent families face major 
challenges that could affect the long-term human capital development of children and put excessive burdens on parents' time.

- DeCesaro and Hemmeter examine the relationship between Medicaid and the unmet health care needs and medical out-of-pocket expenses of child SSI recipients. They find that most child SSI recipients do not have unmet medical needs, in large part because of the availability of Medicaid. However, a concern is that some youth might lose their Medicaid eligibility if they leave SSI as adults. This issue is an especially important consideration in tracking the long-term health outcomes of former child SSI recipients, as well as in designing interventions to serve their long-term needs.

- Hemmeter, Kauff, and Wittenburg focus more specifically on the outcomes of child SSI recipients nearing age 18 to illustrate the variations in transition outcomes across impairment groups. They find that nonhealth factors, particularly education, employment, and social indicators, play an important role in the probability of a child SSI recipient being on adult SSI after age 18. A major concern is that some youth no longer on SSI after age 18 , particularly those with mental disorders other than mental retardation, might not have been sufficiently prepared for life without SSI.

The final two papers examine the YTD interventions geared to serve transition-age (14 to 25) SSI recipients. The combination of intensive supports, strong work incentive waivers, relatively large target populations, and random assignment provides a unique opportunity to test the efficacy of the YTD interventions.

- Fraker and Rangarajan provide an overview of YTD and describe the planned rigorous, randomized field experiment evaluation that will ensure the findings can best serve policy makers and practitioners in developing best practices.

- Luecking and Wittenburg provide a detailed review of how the intervention components were developed for YTD and present case descriptions of how three (nonrandomly selected) youth have used these services successfully to move into employment. These vivid illustrative examples supplement the other, more quantitatively oriented analyses in this volume by providing a more personal perspective of the challenges facing these youth and how a variety of well-coordinated interventions might produce positive outcomes.
In light of the complexities associated with the childhood SSI program, the need to examine the role of employment-oriented interventions from a life-cycle perspective, and a variety of analytical challenges, further research is sorely needed. Future research will be most helpful if it implements a carefully balanced mix of statistical and econometric analyses based on longitudinal data sources with a long time horizon and institutional analyses. Future interventions must be carefully designed to include random assignment, with evaluations based on both rigorous quantitative analysis and qualitative approaches such as case studies and process evaluations. We still need to learn much more about what works - and for whom.

\section{Acknowledgements}

We dedicate this paper to our late friend and colleague, Jeffrey A. Shapiro, who provided careful and conscientious programming assistance for the data analysis in section 4 of this paper and so many other papers over his long career as a dedicated and loyal civil servant. We thank Paul Wehman, editor of the Journal of Vocational Rehabilitation, for supporting this special issue on SSI children in transition. We also express our gratitude to our fellow authors of the papers in this volume - Anne DeCesaro, Tom Fraker, Jeffrey Hemmeter, Jackie Kauff, Rich Luecking, Anu Rangarajan and Stephen Ressler - for their outstanding contributions. We are grateful to Susan Grad, Jeffrey Hemmeter, Robert Weathers, and Susan Wilschke for helpful comments and feedback on an earlier draft. Any remaining errors are our own. The views and opinions expressed in this paper are the authors' and do not reflect the official positions of Mathematica Policy Research, Inc., the Social Security Administration, or any agency of the federal government.

\section{References}

[1] L.Y. Aron, P.J. Loprest and C.E. Steuerle, Serving Children with Disabilities: A Systematic Look at the Programs, Washington, DC: The Urban Institute Press, 1996.

[2] L.Y. Aron and P.J. Loprest, Meeting the Needs of Children with Disabilities, Washington, DC: The Urban Institute Press, 2007.

[3] J. Currie, Healthy, Wealthy, and Wise: Socioeconomic Status, Poor Health in Childhood, and Human Capital Development, NBER Working Paper No. 13987, 2008.

[4] J. Currie, Child health and the intergenerational transmission of human capital, July 2008b. [Available online at http:// www.voxeu.org/index.php?q=node/1422. Accessed February 10, 2009.] 
[5] P.S. Davies and K. Rupp, An overview of the National Survey of SSI Children and Families and related products, Social Security Bulletin 66(2) (2005/2006), 7-20.

[6] A. DeCesaro and J. Hemmeter, Unmet Health Care Needs and Medical Out-of-Pocket Expenses of SSI Children, Journal of Vocational Rehabilitation 30(3) (2009).

[7] P. Decker and C. Thornton, The long-term effects of transitional employment services, Social Security Bulletin 58(4) (1995), 71-81.

[8] M. Duggan and M.S. Kearney, The impact of child SSI enrollment on household outcomes: Evidence from the Survey of Income and Program Participation, NBER Working Paper Series No. 11568 (August 2005).

[9] J.L. Erkulwater, Disability Rights and the American Social Safety Net. Ithaca, NY and London: Cornell University Press, 2006.

[10] T. Fraker and A. Rangarajan, The Social Security Administration's Youth Transition Demonstration Projects, Journal of Vocational Rehabilitation 30(3) (2009).

[11] J. Guryan, E. Hurst and M. Kearney, Parental education and parental time with children, Journal of Economic Perspectives 22(3) (2008), 23-47.

[12] J. Hemmeter, J. Kauff and D.Wittenburg, Changing Circumstances: Experiences of Child SSI Recipients Before and After Their Age-18 Redetermination for Adult Benefits, Journal of Vocational Rehabilitation 30(3) (2009).

[13] L.A. Karoly and P.S. Davies, The impact of the 1996 SSI childhood disability reforms: evidence from matched SIPPSSA data, University of Michigan Retirement Research Center Working Paper WP 2004-079, 2004.

[14] R. Kornfeld and K. Rupp, The net effects of the Project NetWork Return-to-Work Case Management Experiment on participant earnings, benefit receipt, and other outcomes, Social Security Bulletin 63(1) (2000), 12-33.

[15] P. Loprest and D. Wittenburg, Post-transition experiences of former child SSI recipients, Social Service Review 4 (2007), 583-608.

[16] R. Luecking and D.Wittenburg, Providing Supports to Youth with Disabilities Transitioning to Adulthood: Case Descriptions from the Youth Transition Demonstration, Journal of Vocational Rehabilitation 30(3) (2009).

[17] P.W. Newacheck, B. Strickland, J.P. Shonkoff, J.M Perrin, M. McPherson, M. McManus, C. Lauver, H. Fox and P. Arango, An epidemiologic profile of children with special health care needs,Pediatrics 102(1 Pt. 1) (1998), 117-123.

[18] D. Peikes, S. Orzol, L. Moreno and N. Paxon, State Partnership Initiative: Selection of comparison groups for the evaluation and selected impact estimates, Report submitted to the Virginia Commonwealth University and the Social Security Administration, Princeton, NJ: Mathematica Policy Research, Inc., October 31, 2005.

[19] A. Rangarajan, D. Wittenburg, T. Honeycutt and D. Brucker, Programmes to promote employment for disabled people: Lessons from the United States, Department for Work and Pensions, Research Report No 548, 2008.

[20] J. Rogowski, L.A. Karoly, J.A. Klerman, M. Inkelas, M. Rowe and R. Hirscher, Final Report for Policy Evaluation of the Effect of the 1996 Welfare Reform Legislation on SSI Ben- efits for Disabled Children, RAND Report DRU-2559-SSA, submitted to the Social Security Administration, March 2002.

[21] K. Rupp, P.S. Davies, C. Newcomb, H. Iams, C. Becker, S. Mulpuru, S. Ressler, K. Romig and B. Miller, Profile of children with disabilities receiving SSI: Highlights from the National Survey of SSI Children and Families, Social Security Bulletin 66(2) (2005/2006), 21-48.

[22] K. Rupp and S. Bell, Provider incentives and access in the Ticket to Work Program: Implications of Simulations based on the Project Network Field Experiment, in: Paying for Results in Vocational Rehabilitation: Will Provider Incentives Work for Ticket to Work? K. Rupp and S. Bell, eds, Washington, DC: Urban Institute Press, 2003.

[23] K. Rupp and S. Ressler, Family Caregiving and Employment among Parents of Children with Disabilities on SSI, Journal of Vocational Rehabilitation 30(3) (2009).

[24] K. Rupp and C.G. Scott, Determinants of duration on the disability rolls and program trends, in: Growth in Disability Benefits: Explanations and Policy Implications, K. Rupp and D.C. Stapleton, eds, Kalamazoo: W.E. Upjohn Institute for Employment Research, 1998.

[25] J.P. Smith, The impact of childhood health on adult labor market outcomes, Rand Labor and Population Working Paper WR-319, August 2005.

[26] J.P. Smith, The Impact of socioeconomic status on health over the life-course," Journal of Human Resources 42(4) (Fall 2007), 739-764.

[27] Social Security Administration, Annual Report of the Supplemental Security Income Program, Baltimore, MD: Social Security Administration, 2008.

[28] Social Security Administration, Disability Evaluation Under Social Security (Blue Book), SSA Publication No. 64039. Baltimore, MD: Social Security Administration, 2008b. [Available online at http://www.socialsecurity.gov/disability/ professionals/bluebook/. Accessed February 19, 2009.]

[29] Social Security Administration, SSI Annual Statistical Report, 2007, SSA Publication No. 13-11827, Baltimore, MD: Social Security Administration, 2008c.

[30] Social Security Administration, State Assistance Programs for SSI Recipients, SSA Publication No. 13-11975, Baltimore, MD: Social Security Administration, 2008d.

[31] Social Security Administration, The Red Book - A Guide to Work Incentives, SSA Publication No. 64-030, Baltimore, MD: Social Security Administration, 2009. [Available online at http://www.socialsecurity.gov/redbook/. Accessed February 20, 2009.]

[32] B. Trenkamp and M. Wiseman, The Food Stamp Program and Supplemental Security Income, Social Security Bulletin 67(4) (2007), 71-87.

[33] B. Weathers, G. Walter, S. Schley, J. Hennessey, J. Hemmeter and R. Burkhauser, How postsecondary education improves adult outcomes for Supplemental Security Income children with severe hearing impairments, Social Security Bulletin 67(4) (2007), 101-131.

[34] D. Wittenburg and P. Loprest, Early transition experiences of transition-age child SSI recipients: New evidence from the National Survey of Children and Families, Journal of Disability Policy Studies 18(3) (2007), 176-187. 